\title{
BMJ Open Cross-sectional study assessing the addition of contrast sensitivity to visual acuity when testing for fitness to drive
}

\author{
Lucie Spreng, ${ }^{1}$ Bernard Favrat, ${ }^{2,3}$ François-Xavier Borruat, ${ }^{4}$ Paul Vaucher ${ }^{3,5}$
}

To cite: Spreng L, Favrat B, Borruat $\mathrm{F}-\mathrm{X}$, et al. Crosssectional study assessing the addition of contrast sensitivity to visual acuity when testing for fitness to drive. BMJ Open 2018;8:e018546. doi:10.1136/ bmjopen-2017-018546

- Prepublication history for this paper is available online. To view these files, please visit the journal online (http://dx.doi. org/10.1136/bmjopen-2017018546).

Received 6 July 2017 Revised 21 November 2017 Accepted 30 November 2017

Check for updates

${ }^{1}$ Doctoral School of Medicine, Faculty of Medicine and Biology, University of Lausanne, Lausanne, Switzerland ${ }^{2}$ Department of Ambulatory Care and Community Medicine, University of Lausanne, Lausanne, Switzerland ${ }^{3}$ Unit of Psychology and Traffic Medicine, University Centre of Legal Medicine LausanneGeneva, University Hospital of Lausanne (CHUV), Lausanne, Switzerland

${ }^{4}$ Ophthalmology Department, Jules-Gonin Eye Hospital, University of Lausanne, Lausanne, Switzerland ${ }^{5}$ aR\&D, School of Health Sciences Fribourg, University of Applied Sciences and Arts Western Switzerland (HES-SO), Fribourg, Switzerland

Correspondence to Dr Paul Vaucher; paul.vaucher@hes-so.ch

\section{ABSTRACT}

Objectives The aim of this study is to quantify the importance of loss of contrast sensitivity (CS) and its relationship to loss of visual acuity (VA), driving restrictions and daytime, on-road driving evaluations in drivers aged $70+$

Design A predictive cross-sectional study.

Setting Volunteer participants to a drivers' refresher course for adults aged $70+$ delivered by the Swiss Automobile Club in western Switzerland from 2011 to 2013.

Participants 162 drivers, male and female, aged 70 years or older.

Clinical predictors We used a vision screener to estimate VA and the The Mars Letter Contrast Sensitivity Test to test CS.

Outcomes We asked drivers to report whether they found five driving restrictions useful for their condition; restrict driving to known roads, avoid driving on highways, avoid driving in the dark, avoid driving in dense traffic and avoid driving in fog. All participants also underwent a standardised on-road evaluation carried out by a driving instructor.

Results Moderate to severe loss of CS for at least one eye was frequent $(21.0 \%(95 \% \mathrm{Cl} 15.0 \%$ to $28.1 \%))$ and often isolated from a loss of VA (11/162 cases had a VA $\geq 0.8$ decimal and a CS of $\leq 1.5 \log (\mathrm{CS}) ; 6.8 \%(95 \% \mathrm{Cl} 3.4 \%$ to $11.8 \%))$. Drivers were more likely $\left(\mathrm{R}^{2}=0.116, \mathrm{P}=0.004\right)$ to report a belief that self-imposed driving restrictions would be useful if they had reduced CS in at least one eye. Daytime evaluation of driving performance seems limited in its ability to correctly identify difficulties related to CS loss (VA: $R^{2}=0.004, P=0.454 ; C S: R^{2}=0.006, P=0.332$ ). Conclusion CS loss is common for older drivers. Screening CS and referring for cataract surgery even in the absence of VA loss could help maintain mobility. Reduced CS and moderate reduction of VA were both poor predictors of daytime on-road driving performances in this research study.

\section{INTRODUCTION}

Within an ageing population, the question of whether elderly people should be managed differently with regard to their driving licence is becoming more and more relevant. The literature predicts that by the year 2020, 20\% of licensed drivers will be older than 65 years. ${ }^{1}$ In Switzerland, in

\section{Strengths and limitations of this study}

Participants of 70 years of age or older were drivers from the general population. We did not concentrate on those with known health issues or those that had known driving history.

Drivers were free to speak openly about their health and driving experiences, given data were collected anonymously and there was no threat for their licence.

- Observer bias cannot be totally excluded, given information on visual performance and driving restrictions was collected by the same researcher.

- The on-road driving tests were done during the day; we cannot therefore exclude that performances would be different with lower luminance.

2015, 1797 drivers of 70 years of age or more were involved in a road accident with severe injury or death $\left(0.02 \%\right.$ of the population) ${ }^{2}$ This population has been shown to be more at risk. Accidents involving aged drivers are much more likely to result in hospital admissions or fatalities due to such drivers' own health vulnerabilities. ${ }^{3-6}$ In other words, older drivers and health issues is more a public health concern for their own security rather than for others'. ${ }^{78}$ Being able to drive a vehicle is, however, very important for the autonomy, the self-esteem and the quality of life of the elderly. ${ }^{1}$ It is linked to a lower mortality risk. ${ }^{9}$ Without this ability, the resulting loss of independence induces a higher risk of isolation, depression and associated functional impairment. ${ }^{9-11}$

In Switzerland, non-professional drivers who are 70 years of age or older have to undergo a compulsory medical assessment of their fitness to drive every 2 years. ${ }^{12}$ The law specifies that the physician is responsible of verifying the absence of psychological, neurological, musculoskeletal, cardiovascular, respiratory or metabolic (diabetes) disorders that could affect driving. Like in many other countries, the legislation 
also specifies that drivers' vision and hearing must be checked. ${ }^{412}$

For the elderly, health decline and visual impairments are the most common causes that lead to driving cessation. ${ }^{13-16}$ Older drivers have difficulties adapting their vision to low light conditions, recognising on-road and roadside objects in low light conditions and recovering from glare. ${ }^{17}$ Loss of visual acuity (VA) has been shown to be associated with the avoidance of driving long distances or in unfamiliar areas. Loss of contrast sensitivity (CS) is, on the other hand, associated with the avoidance of driving at night or in conditions of reduced luminosity. ${ }^{18}$ At age $75+, 39.8 \%$ of female drivers and $28.8 \%$ of male drivers report restricting their driving due to problems with their eyesight. ${ }^{19}$ Drivers who think their vision has worsened will restrict their driving most, even if their binocular vision is not affected. ${ }^{19}$ Those that have a binocular CS loss $<1.4$ $\log (\mathrm{CS})$ are 2.5 (95\% CI 1.2 to 3.0) times more likely to cease driving altogether. ${ }^{20}$

High contrast VA is the most commonly used measure of vision in assessing fitness to drive, but there are other measures of vision such as CS that are more discriminating. The true value of asking aged drivers to sacrifice their mobility because they have reduced vision is unknown, and there is no existing evidence that supports the belief that screening VA under photopic conditions improves road safety. ${ }^{10}$ 13 21-23 A population-based survey has shown that $2.6 \%$ of those currently driving have a VA lower than the legal limit $(<0.5$ decimal $)$ without them being more at risk of having accidents. ${ }^{24}$ It is commonly admitted that screening for VA alone is inappropriate for assessing full visual function; ${ }^{10}$ it is also, at best, a very weak means of predicting road accidents, ${ }^{6}{ }^{24}$ and is also a bad predictor of night driving ability. ${ }^{14}$ For some ocular pathologies, cataracts, for example, CS loss might be more influential than VA as a contributory cause of accidents. ${ }^{6}{ }^{24}$ Furthermore, drivers with a monocular or binocular reduction of CS are more likely to be involved in a collision that is their fault than are drivers with reduced VA. ${ }^{25}$ For the moment, European guidelines and legislations provide norms and indications for VA, $\geq 0.5$ decimal; visual field, $\geq 120^{\circ}$; no diplopia; no important deterioration of twilight vision and no major increase in glare sensitivity. But little is known regarding the usefulness of also screening for loss of CS, which could provide more insight into the patient's ability to drive at night. This would make it possible to restrict driving to daylight conditions rather than have people cease driving-measures that have been shown to be effective in reducing risks. ${ }^{26}$

The aim of this study is to: (1) estimate the prevalence of drivers aged 70+ who are concerned by CS loss, (2) evaluate the strength of the association between loss of VA and CS and (3) estimate the added value of measuring CS over VA when trying to evaluate self-regulations of driving or on-road driving performance.
METHODS

\section{Design}

We designed an exploratory, cross-sectional, pragmatic study combining the clinical and on-road evaluation of older drivers attending a refresher course in Switzerland.

\section{Population}

From 2011 to 2013, all residents aged 70 years or more $(n=16858)$ of four regions of Vaud, Switzerland received an invitation to participate in a refresher course in driving competencies, provided by the Swiss Automobile Club. Of these, 1004 participated $(5.1 \%$ of all concerned senior drivers) and were invited to voluntarily and anonymously be screened for medical conditions within the Guarding Aged drivers against accidents project (GarAge). There was a $44.9 \%$ acceptance rate. Measurements of CS were added in October 2012. To be included in this study, participants had to hold a valid Swiss driving licence, be community residents of the Canton of Vaud in Switzerland, be aged 70 years or older, and have CS evaluated separately for each eye.

\section{Visual acuity}

Monocular and binocular distance VA were measured using a vision screener called Visiotest (manufacturer Essilor). This device has been shown to have a sensitivity of $100 \%$ and a specificity of $88.1 \%{ }^{27}$ to detect vision deficiency compared with an examination of vision carried out by an optometrist. Luminosity was set to $320 \mathrm{~cd} / \mathrm{m}^{2}$ with optotype contrast close to $100 \%$. All tests were carried out with both eyes open. We first tested the VA of the left eye, then the right and finally both eyes simultaneously. All tests were carried out with optical corrections for vision at a distance-that is, to say, patients' glasses.

\section{Contrast sensitivity}

The Mars Letter Contrast Sensitivity Test was used to evaluate CS. $^{28-30}$ It consists of three cardboard charts with 48 letters each. From one letter to the next, there was a decrease in contrast of a constant factor of $0.04 \mathrm{log}$ units. The chart is held $50 \mathrm{~cm}$ away from the eyes. The MARS chart has the advantage over the Pelli-Robson chart of being smaller, more portable and more easily uniformly illuminated. ${ }^{28}$ This test is at least as reliable or more so than the Pelli-Robson test. ${ }^{28-30}$ In our study, we decided to set the threshold for detecting moderate to severe contrast loss for CS at $<1.5 \log (\mathrm{CS}) .{ }^{31} 32$

\section{Ancillary tests}

In addition to VA and CS, we also evaluated horizontal visual fields; visual processing, using the useful field of view (UFOV) $;^{33}$ overall cognitive function, using the Montreal Cognitive Assessment; ${ }^{34}$ executive function and visuospatial search, using the Trail Making Task (parts A and $\mathrm{B})^{35}$ and motor function, using the Timed Up-and-Go Test. $^{36}$ 


\section{Driving history and self-imposed driving restrictions}

Participants were questioned on any accidents they may have had in the past and their average weekly distance driven. To investigate relevant driving restriction strategies, we reviewed the literature and identified 13 questions related to tactical or strategic compensations that were reported by older drivers. These were reformulated so that drivers could report their perceived usefulness to their own, respective, situations, using a five-step Likert scale (ie, essential, very useful, useful, slightly useful and useless). We then used data from 445 drivers to derive and test the psychometric values of questions related to driving cessation. Item reduction was carried out using polychoric, correlation-iterated principal factor analysis with orthogonal rotation. Items with a uniqueness value of 0.6 or more were excluded and the analysis was run over again. Principal component analysis revealed a single factor with an eigenvalue of 2.62; the second factor had an eigenvalue of 0.19 . The five items for this factor were: restrict driving to known roads, avoid driving on highways, avoid driving in the dark, avoid driving in dense traffic and avoid driving in fog. The internal coherence of these items was acceptable (Cronbach's alpha $=0.680$ ). The driving restriction score was obtained by adding up the values of each individual question about the usefulness of these specific driving restriction strategies. The score therefore ranges from 0 to 20 with high scores corresponding to increased self-restriction.

\section{On-road driving evaluation}

The procedure has been previously described in two publications. ${ }^{35} 37$ Twelve driving instructors, blinded to the clinical assessment, were engaged in the study. Each participant drove once, with one of the instructors, on a $45 \mathrm{~min}$ route on the open road, including urban and rural sections, secondary and principal roads and highways, simple and complex intersections, 'roundabouts' (circular intersections with changing on-road priorities), traffic signals and complex lane selections. Instructors reported their 'gestalt' evaluation of driving performance as 'good' or 'sufficient' for the following criteria: respecting road regulations, handling the vehicle, speed adaptation, correct positioning on the road, comfort, behaviour towards other road users, observation and anticipation. Driving competencies were summarised as excellent (no lapse), good (lapses reported for one or two items), moderate (lapses reported for three to five items) or poor (lapses reported for six to eight items). This scoring method identified a unique dimension (eigenvalue $=5.1$ ) and had a good fit to an overall trait (R1c=12.2, df=14, $\mathrm{P}=0.565$ ).

\section{Statistical methods}

Significance level was set at $\alpha=0.05$ and all estimates are provided with $95 \%$ CIs. Sample size was estimated with a power of $80 \%$ to detect a determinant of correlation $\left(R^{2}\right)$ of 0.25 . This required a minimum of 124 participants.
For comparability and to assure linearity for regression analysis, both VA and CS were used on their log scale (ie, $\log$ (minimum angle of resolution) and $\log (\mathrm{CS})) .{ }^{18}$ Associations between VA and CS were analysed for all tested eyes adjusting for a lack of independence of values coming from the same individuals, using mixed-effect linear regression. To test associations with self-imposed driving restrictions and the on-road evaluation, we used the value observed for both eyes, for the worst eye or the absolute difference of values between both eyes as independent variables. We then used linear regression analysis to test associations with and without adjustment for possible confounders (ie, cognitive deficits, motor deficits, age and gender). To verify the assumption of linearity, we used likelihood ratio tests to compare models using dependent variables as a continuous variable instead of dichotomised ordinal variables. We compared the added value of using CS to VA alone using a likelihood ratio test between both models. $\mathrm{P}<0.05$ meant that $\mathrm{CS}$ improved the prediction of driving restrictions or on-road performances.

Given most outcome measures were expected to be highly correlated, no adjustments were made for multiple testing. Only subjects with full data were included in the analysis. All statistics were planned prior to analysis and were run using STATA V.14.0 (Stata Statistical Software: Release V.14.0, StataCorp).

\section{Ethical standards}

All participants provided their written, informed consent to participate. It was performed in accordance with the ethical standards of the 2008 amended Declaration of Helsinki (Seoul).

\section{RESULTS \\ Population description}

The average acceptance rate over all four regions to attend the refreshing course was of $5.1 \%$. Between

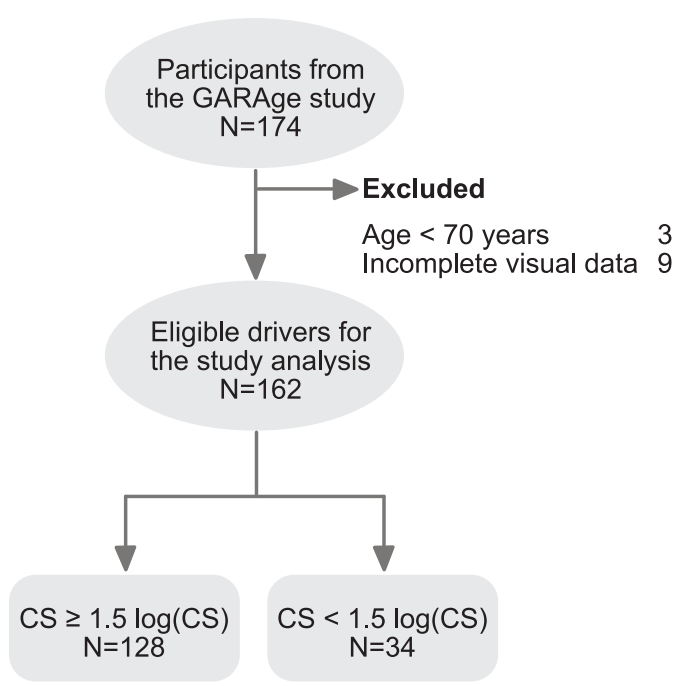

Figure 1 Participant flow chart. CS, contrast sensitivity; GarAge, Guarding Aged drivers against accidents project . 
Table 1 Description of the population

\begin{tabular}{|c|c|c|c|c|c|c|c|}
\hline & \multicolumn{2}{|c|}{$\begin{array}{l}\text { All participants } \\
(\mathrm{n}=162)\end{array}$} & \multicolumn{2}{|c|}{$\begin{array}{l}\text { Both eyes with } \log (\mathrm{CS}) \geq 1.5 \\
(\mathrm{n}=128,79 \%)\end{array}$} & \multicolumn{2}{|c|}{$\begin{array}{l}\text { Worst eye with } \log (C S)<1.5 \\
(n=34,21 \%)\end{array}$} & \multirow[b]{2}{*}{ P value* } \\
\hline & Mean (SD) & $\begin{array}{l}\text { Median } \\
\text { (p5-p95) }\end{array}$ & Mean (SD) & $\begin{array}{l}\text { Median } \\
\text { (p5-p95) }\end{array}$ & Mean (SD) & $\begin{array}{l}\text { Median } \\
\text { (p5-p95) }\end{array}$ & \\
\hline Age & $76.1(4.73)$ & $75.2(70.8-84.9)$ & $75.9(4.64)$ & $74.9(70.8-84.9)$ & $77.0(5.0)$ & $75.6(70.6-88.7)$ & 0.195 \\
\hline \multicolumn{8}{|l|}{ Functional mobility } \\
\hline TUG test $(\mathrm{s}) \dagger$ & $9.49(2.65)$ & $9.0(6.8-15.1)$ & $9.16(2.32)$ & $8.8(6.3-13.1)$ & $10.7(3.38)$ & $10.1(6.1-16.3)$ & 0.002 \\
\hline \multicolumn{8}{|l|}{ Cognitive state } \\
\hline MoCa (points) $\ddagger$ & $26.5(2.63)$ & $27(21-30)$ & $26.5(2.53)$ & $27(21-30)$ & $26.24(2.99)$ & 27 (19-29) & 0.561 \\
\hline \multicolumn{8}{|l|}{ Driving } \\
\hline $\begin{array}{l}\text { Distance }(\mathrm{km}) / \\
\text { week }\end{array}$ & $238(224)$ & $200(60-500)$ & $234(239)$ & $195(60-500)$ & $253(159)$ & $225(40-550)$ & 0.668 \\
\hline Restriction score & $2.3(2.78)$ & $1(0-8)$ & $1.88(2.46)$ & $1(0-6)$ & $3.68(3.45)$ & $3(0-12)$ & $<0.001$ \\
\hline \multicolumn{8}{|l|}{ Vision } \\
\hline VA bilateral§ & $1.02(0.20)$ & $1.0(0.6-1.2)$ & $1.06(0.17)$ & $1.2(0.8-1.2)$ & $0.88(0.24)$ & $1.0(0.4-1.2)$ & $<0.001$ \\
\hline VA best eye§ & $0.96(0.22)$ & $1.0(0.6-1.2)$ & $0.99(0.21)$ & $1.0(0.6-1.2)$ & $0.85(2.05)$ & $0.8(0.6-1.2)$ & $<0.001$ \\
\hline VA worst eye§ & $0.72(0.31)$ & $0.8(0.2-1.2)$ & $0.79(0.27)$ & $0.8(0.4-1.2)$ & $0.46(0.31)$ & $0.4(0.0-1.0)$ & $<0.001$ \\
\hline Visual fieldף & $183(16)$ & $180(160-200)$ & $185(14)$ & $180(160-200)$ & $179(23)$ & $180(140-200)$ & 0.059 \\
\hline CS bilateral ${ }^{\star *}$ & $1.72(0.06)$ & $1.72(1.6-1.76)$ & $1.73(0.04)$ & $1.74(1.68-1.76)$ & $1.66(0.09)$ & $1.68(1.48-1.76)$ & $<0.001$ \\
\hline CS best eye $e^{\star *}$ & $1.69(0.06)$ & $1.72(1.56-1.76)$ & $1.73(0.04)$ & $1.74(1.68-1.76)$ & $1.66(0.09)$ & $1.68(1.48-1.76)$ & $<0.001$ \\
\hline CS worst eye & $1.57(0.25)$ & $1.64(1.24-1.72)$ & $1.66(0.06)$ & $1.68(1.52-1.72)$ & $1.25(0.38)$ & $1.44(0.04-1.48)$ & $<0.001$ \\
\hline
\end{tabular}

*Student's t-test comparing groups with or without contrast sensitivity loss.

†If $\geq 13.5 \mathrm{~s}$ : functional mobility difficulties. One person could not do the test and was not assessed.

łlf $<26$ points: cognitive difficulties.

§In decimal.

IVisual field in degrees.

${ }^{\star *}$ Expressed in $\log (\mathrm{CS})$ : considered as normal if $\geq 1.5 \log (\mathrm{CS})$ and restricted if $<1.5 \log (\mathrm{CS})$.

CS, contrast sensitivity; MoCa, Montreal Cognitive Assessment; p5, fifth percentile; p95, 95th percentile; TUG, Timed Up-and-Go Test; VA, visual acuity.

October 2012 and September 2013, 174 older drivers volunteered to participate in the GarAge study; complete data proved available for 162 of them (figure 1). Visual tests were partially available for seven of the nine drivers who were excluded. Five had a VA of 0.8 decimal or more for each of their eyes, one had 0.6 decimal for both eyes and one had 0.6 decimal for one eye and 1.0 decimal for the other. The majority of participants were men $(66.7 \%$, $\mathrm{n}=108)$. One-third $(35.4 \%)$ had had an incomplete education history $(<12$ years of schooling). Forty-three of the drivers $(26.5 \%)$ had been involved in an accident during the previous 2 years; eight drivers had had to file a claim on their vehicle insurance and only one accident caused injury. Driving instructors considered $46.4 \%$ of drivers to have excellent driving competencies, $30.0 \%$ to have good competencies, $16.3 \%$ to have moderate competencies and $7.3 \%$ to have poor competencies. Having good or moderate competencies did not prevent drivers from considering self-imposed driving restrictions useful; only $35 \%$ (56 persons) reported all five restrictions as useless to them. An important number of participants had a health condition that could affect driving performances $(\mathrm{n}=85,52.5 \%)$. Further details on participating drivers are provided in table 1 .

\section{Prevalence of moderate or severe CS loss}

Twenty-one per cent (95\% CI $15.0 \%$ to $28.1 \%$ ) of drivers had a moderate or severe CS loss for at least one eye. Twelve cases having a severe loss $(7.4 \%$; 95\% CI 3.9\% to $12.6 \%)$. We also observed two cases $(1.2 \%$; $95 \%$ CI $0.1 \%$ to $4.4 \%)$ of CS loss in both eyes. The two cases we observed with binocular CS loss were a 82-year-old male driver who had severe binocular CS $\operatorname{loss}(\log (\mathrm{CS})=1.28)$ without having lost his VA (0.8 decimals), and a 78-year-old female driver with a moderate CS loss of $1.48 \log (\mathrm{CS})$ but a VA of 1.0 decimals. Both drivers had no cognitive deficits and were given an excellent daytime on-road driving evaluation and both reported only slightly limiting their night driving.

We also observed that drivers with low CS tended to also have slower functional mobility, identified more self-imposed driving restrictions as being useful and had lower VA (table 1).

\section{Associations between VA and CS}

When screening for vision, measuring VA alone had us take into account $39.7 \%$ of the variance we observed when measuring $\mathrm{CS}(\mathrm{P}<0.001)$. One-third of the 39 tested eyes that had a $\log (\mathrm{CS})<1.5$ had a VA of 0.8 decimal or better. Adding CS would have made it possible to detect 
A. On-road driving score

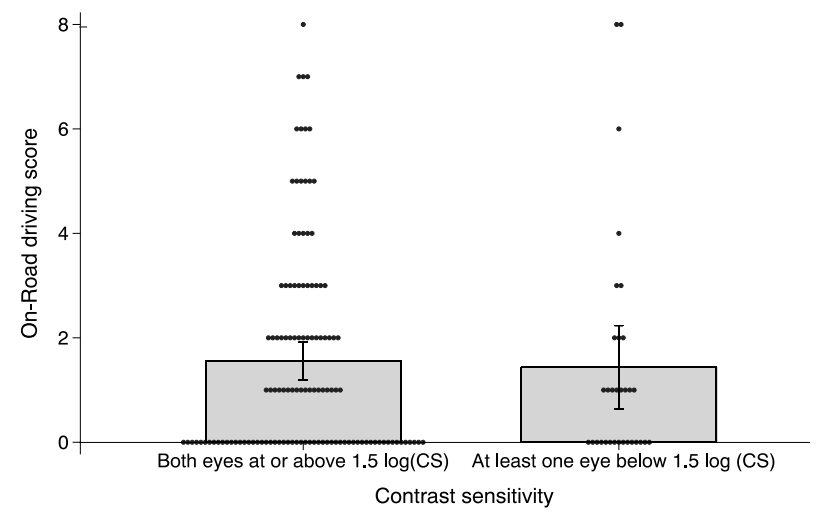

B. Driving restriction score

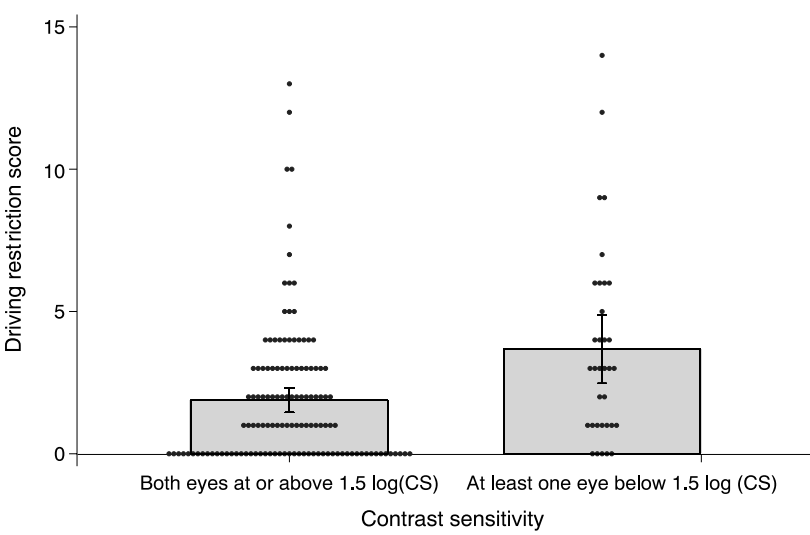

Figure 2 Driving performances between drivers with normal contrast sensitivity (CS) and those with low CS. (A) On-road driving score ranges from 0 to 8 with higher scores indicating more errors. (B) Driving restriction score ranges from 0 to 20 with higher scores indicating higher levels of restriction.

unsuspected vision deficits in 11 drivers $(6.8 \%$; $95 \%$ CI $3.4 \%$ to $11.8 \%$ ).

\section{Association and added value of CS for predicting the perceived utility of self-imposed driving restrictions}

Drivers were more likely $\left(\mathrm{R}^{2}=0.116, \mathrm{P}=0.004\right)$ to report finding driving restrictions potentially useful if they had at least one eye that had reduced CS (figure 2; table 2). This was particularly the case for avoiding driving in the dark $\left(\mathrm{R}^{2}=0.056, \mathrm{P}=0.022\right)$ and in fog $\left(\mathrm{R}^{2}=0.083, \mathrm{P}=0.001\right)$. The only significant association for VA, on the other hand, was between binocular loss and avoiding driving in the dark $\left(\mathrm{R}^{2}=0.065, \mathrm{P}=0.010\right)$. The observed added value of using CS instead of VA was, however, not significant $(\mathrm{P}=0.345)$. We also observed that drivers who recognised the usefulness of any form of driving restriction were 3.1 times more likely to have moderate CS loss for at least one eye (CS $\leq 1.5 \log (\mathrm{CS}))$. The association between loss of CS and recognising the usefulness of driving restrictions remained significant even after adjustment for cognitive decline, motor function, age and gender.
Association and added value of CS for predicting daytime onroad driving performance

Daytime driving performance was unrelated to CS or VA loss (figure 2; table 3).

\section{DISCUSSION}

In our study, one driver aged $70+$ out of five $(21 \%)$ had a loss of CS $(<1.5 \log (\mathrm{CS}))$ in at least one eye. Furthermore, our results suggest that $6.8 \%$ of all drivers aged $70+$ start experiencing difficulties in low illumination without their VA being affected in normal light conditions (VA $\geq 0.5$ decimal). Our study confirmed the clear association between CS loss and the perceived utility of driving restrictions even if the added value of using CS instead of VA was not significant. The feeling of impairment was more related to only one eye being affected or to having an important difference between the two eyes than to binocular impairment. Our results also confirmed that loss of CS had no association to daytime on-road driving performance. Our results therefore reveal two important facts about vision loss and driving. First, many people consider restrictions as being useful when their loss only concerns one eye and is not believed to affect their driving performance. Second, standard on-road driving evaluations have important limitations, given that they cannot reveal the difficulties experienced in more difficult situations with less light as reported by drivers. This suggests that standard on-road tests should not be considered as a gold standard for assessing fitness to drive unless these tests are adapted to the conditions in which difficulties might arise.

One of the strengths of this study is that it studies drivers that had not been selected for medical reasons or due to the fact that they had experienced driving difficulties. This provides better indication on the usefulness of medical screening procedures targeting all drivers. Considering the worst eye also improved our understanding of what causes people to consider driving restrictions. The limitations of this study are the limited number of participants with severe vision impairment and the limited precision of our vision screening tests. Given very few drivers in our sample had important CS loss in both eyes, we cannot exclude that such conditions would also affect daytime on-road evaluations. Furthermore, some participants certainly wore glasses that did not optimally correct their refraction abnormalities. The Mars test is performed at reading distance $(50 \mathrm{~cm})$, whereas VA is tested at distance. Therefore, some discrepancies between the results from each test could arise from refraction problems instead of indicating a true lack of association between VA and CS. Finally, we did not collect information about past cataract operations or present diagnosis of cataract, making it difficult to document patterns in access to surgery.

When comparing our results to the existing literature, other studies have found that driving with a loss of CS or a loss of VA leads to drivers tending to report difficulties experienced while driving. ${ }^{15} 18243839$ Difficulties 
Table 2 Advantages of CS over VA for determining driving restriction

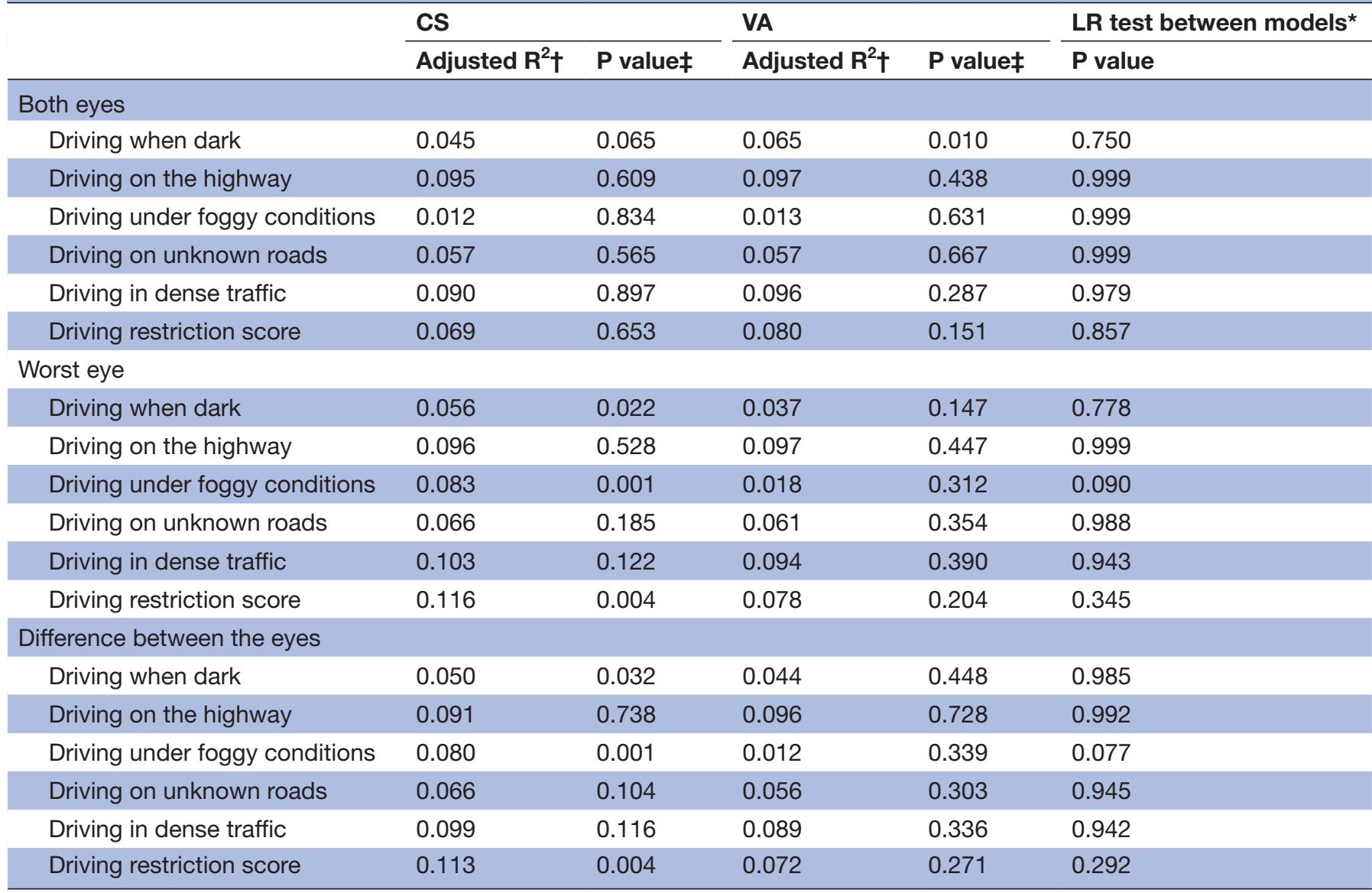

*Best model over worst. $P$ values under 0.05 would mean the test with the highest $\mathrm{R}^{2}$ is significantly better than the other visual test. †Adjusted $R^{2}$ for entire model. $R^{2}$ corresponds to the test's contribution in explaining restrictions and ranges from 0 to 1 . $\ddagger$ Significance of contribution of visual component.

CS, contrast sensitivity; LR, likelihood ratio; VA, visual acuity.

seem to arise especially in low illumination ${ }^{14}$ and increase the probability of driving restrictions being required. Restricting driving and avoiding driving at night, dawn or dusk seem to be appropriate measures for reducing risks. ${ }^{5}$ Men, more than women and people with cognitive decline, often deny experiencing or simply do not experience any vision problems and therefore do not want or do not feel the need to have their driving practices restricted. ${ }^{14041}$ This is one of the situations in which a deeper visual screening is needed. However, restricted

Table 3 Advantages of CS over VA for determining on-road driving score $(0-3)^{\star}$

\begin{tabular}{|c|c|c|c|c|c|}
\hline & \multicolumn{2}{|l|}{ cs } & \multicolumn{2}{|l|}{ VA } & \multirow{2}{*}{$\begin{array}{l}\text { LR test between } \\
\text { modelst }\end{array}$} \\
\hline & $\mathbf{R}^{2} \ddagger$ & $P$ value§ & $\mathbf{R}^{2} \ddagger$ & $\mathbf{P}$ value§ & \\
\hline \multicolumn{6}{|l|}{ Both eyes } \\
\hline On-road driving score $(0-3)$ & 0.0001 & 0.895 & 0.00 & 0.946 & 0.9935 \\
\hline \multicolumn{6}{|l|}{ Worst eye } \\
\hline On-road driving score $(0-3)$ & 0.0062 & 0.332 & 0.0037 & 0.454 & 0.824 \\
\hline \multicolumn{6}{|l|}{ Difference between the eyes } \\
\hline On-road driving score $(0-3)$ & 0.059 & 0.411 & 0.057 & 0.568 & 0.999 \\
\hline
\end{tabular}

${ }^{*}$ Excellent $=0$, Good $=1$, Moderate $=2$, Poor $=3$.

TP values under 0.05 mean that CS improved the prediction of on-road driving scores compared with VA alone.

$\ddagger$ Crude $R^{2}$ were used instead of adjusted $R^{2}$ given values were close to 0 and adjustment methods become inadequate. $R^{2}$ corresponds to the test's contribution in explaining on-road driving scores and ranges from 0 to 1.

§Significance of contribution of visual component.

CS, contrast sensitivity; LR, likelihood ratio; VA, visual acuity. 
driving has also been shown to reduce risks to the minimum for those experiencing cognitive decline. ${ }^{42} \mathrm{We}$ conclude that recommendations to reduce driving in the dark require at least the measurement of $\mathrm{CS}$ or the testing of VA in low illumination. ${ }^{14}$ This has been recommended by the Deutsche Ophthalmologische Gesellschaft since 2008 when evaluating fitness to drive. ${ }^{43}$ Existing on-road tests, mainly done in high illumination, are not suited for detecting difficulties related to loss of CS. If on-road evaluation is to be considered as a reference standard for fitness to drive, it might be necessary to adapt the driving tests and also assess performances in places with low luminosity. In clinical settings, it might be relevant to test CS using free, computer-based solutions or by simply questioning the drivers concerned. ${ }^{44}$ The vision and night driving questionnaire (VND-Q) was developed for this purpose and includes nine simple questions that drivers can answer prior to their medical examination. ${ }^{45} 46$

We must not forget that a decrease in $\mathrm{CS}$ and/or $\mathrm{VA}^{47}$ can be the major symptom of several ocular disorders, like cataracts, which affect half of adults by the time they reach 75 years of age. ${ }^{6}$ Many people can live a long time with a cataract before a diagnosis is made and surgery is performed. ${ }^{22}$ Unfortunately, drivers with a cataract or cataracts, even involving only one eye, have 2.5 times more risk of causing a car crash than those without a cataract. $^{62247}$ This is why general practitioners should be very vigilant when patients talk about difficulties experienced when driving at night or under foggy conditions. Impaired vision should always be investigated even if patients are reluctant, because it can often be corrected with either medical or surgical management, with subsequent improvement of visual function. ${ }^{624}$ Following cataract surgery, patients can often even drive again at night and/or under foggy conditions with a decreased risk of being involved in a car crash. ${ }^{6}$ Adequate management might avoid unneeded self-restriction or, even worse, unneeded driving cessation.

When assessing fitness to drive, the role of vision screening is more about targeting appropriate driving restrictions than recommending driving cessation. ${ }^{26}$ Some drivers expose themselves to excessive risks by driving in the dark. On the other hand, many drivers, especially women, tend to unnecessarily restrict their driving due to vision deficits in one eye alone ${ }^{19}$ Referring patients to ophthalmologists, occupational therapists or driving instructors to compensate appropriately for vision loss in one eye could help some drivers overcome their fear of driving.

\section{CONCLUSION}

Loss of CS could concern up to one older driver out of five and often occurs without affecting VA. Those with CS loss tend to be more likely to avoid driving at night, in bad weather or under foggy conditions. Visual screening including CS would help detect ophthalmic diseases earlier and refer patients for surgery before their condition affects their driving. This remains, however, controversial given vision status was poorly associated to driving performances for both VA and CS in this research study. Further research is needed to evaluate the impact of vision screening on road accidents.

Acknowledgements We thank Frederique Margot for calling all the participants and setting up the appointments, the 12 driving instructors who assessed driving performance, Sylvie Hautle and the Swiss Automobile Club for organising the refresher courses and letting us use their facilities, and Dave Brooks (ELCS) for editing our English.

Contributors PV and BF applied for and obtained the grants for this study. PV wrote the protocol, managed the staff, recruited participants and monitored data collection. BF was the principal investigator. LS and PV ran the analysis. LS, BF, F-XB and PV interpreted the results; LS and PV wrote the manuscript; all authors approved the final draft.

Funding This study was financed by a grant accorded for research in 2011 by the Department of Medicine and Community Health of the University Hospital of Lausanne, Switzerland.

Disclaimer The funder had no influence on the design, the collection, the analysis and the interpretation of data; on the writing of the manuscript or on the decision to submit the manuscript for publication.

Competing interests None declared.

Patient consent Obtained.

Ethics approval The protocol was approved by the official state ethics committee for the Canton of Vaud (www.cer-vd.ch) under the reference CE 157/2011.

Provenance and peer review Not commissioned; externally peer reviewed.

Data sharing statement Data is made available on request to the corresponding author or francois.mooser@hefr.ch. It is not made publicly available for confidentiality to be maintained. Health data could be linked and merged to existing non-anonymised databases including those held by automobile insurance companies.

Open Access This is an Open Access article distributed in accordance with the Creative Commons Attribution Non Commercial (CC BY-NC 4.0) license, which permits others to distribute, remix, adapt, build upon this work non-commercially, and license their derivative works on different terms, provided the original work is properly cited and the use is non-commercial. See: http://creativecommons.org/ licenses/by-nc/4.0/

(c) Article author(s) (or their employer(s) unless otherwise stated in the text of the article) 2018. All rights reserved. No commercial use is permitted unless otherwise expressly granted.

\section{REFERENCES}

1. Adler G, Rottunda S. Older adults' perspectives on driving cessation. $J$ Aging Stud 2006;20:227-35.

2. Niemann S, Achermann Stürmer Y, Bianchi G, et al. STATUS 2016: statistique des accidents non professionnels et du niveau de sécurité en Suisse; circulation routière, sport, habitat et loisirs. bpa 2016.

3. Ryan GA, Legge M, Rosman D. Age related changes in drivers' crash risk and crash type. Accid Anal Prev 1998;30:379-87.

4. Wagner JT, Müri RM, Nef T, et al. Cognition and driving in older persons. Swiss Med Wkly 2011;140:w13136.

5. Owsley C, Stalvey BT, Phillips JM. The efficacy of an educational intervention in promoting self-regulation among high-risk older drivers. Accid Anal Prev 2003;35:393-400.

6. Owsley C, Stalvey BT, Wells J, et al. Visual risk factors for crash involvement in older drivers with cataract. Arch Ophthalmol 2001;119:881-7.

7. Langford J, Bohensky M, Koppel S, et al. Do older drivers pose a risk to other road users? Traffic Inj Prev 2008;9:181-9.

8. Braver ER, Trempel RE. Are older drivers actually at higher risk of involvement in collisions resulting in deaths or non-fatal injuries among their passengers and other road users? Inj Prev 2004;10:27-32.

9. Marottoli RA, Glass TA, Glass TA, et al. Consequences of driving cessation: decreased out-of-home activity levels. J Gerontol B Psychol Sci Soc Sci 2000;55:S334-40. 
10. Desapriya E, Harjee R, Brubacher J, et al. Vision screening of older drivers for preventing road traffic injuries and fatalities. Cochrane Database Syst Rev 2014;2:CD006252.

11. Anstey KJ, Wood J, Lord S, et al. Cognitive, sensory and physical factors enabling driving safety in older adults. Clin Psychol Rev 2005;25:45-65.

12. Merour A, Favrat B, Borruat F. Exigences visuelles pour la conduite. Rev Med Suisse 2014;10:2252-7.

13. Owsley C, McGwin G. Vision impairment and driving. Surv Ophthalmol 1999;43:535-50.

14. Gruber N, Mosimann UP, Müri RM, et al. Vision and night driving abilities of elderly drivers. Traffic Inj Prev 2013;14:477-85.

15. Gilhotra JS, Mitchell P, Ivers R, et al. Impaired vision and other factors associated with driving cessation in the elderly: the blue mountains eye study. Clin Exp Ophthalmol 2001;29:104-7.

16. Dellinger AM, Sehgal M, Sleet DA, et al. Driving cessation: what older former drivers tell us. J Am Geriatr Soc 2001;49:431-5.

17. Desapriya $\mathrm{E}$, Wijeratne $\mathrm{H}$, Subzwari $\mathrm{S}$, et al. Vision screening of older drivers for preventing road traffic injuries and fatalities. Cochrane Database Syst Rev 2011:CD006252.

18. Freeman EE, Muñoz B, Turano KA, et al. Measures of visual function and their association with driving modification in older adults. Invest Ophthalmol Vis Sci 2006;47:514-20.

19. Ragland DR, Satariano WA, MacLeod KE. Reasons given by older people for limitation or avoidance of driving. Gerontologist 2004:44:237-44.

20. Freeman EE, Muñoz B, Turano KA, et al. Measures of visual function and time to driving cessation in older adults. Optom Vis Sci 2005;82:765-73.

21. Owsley C, Wood JM, McGwin G. A roadmap for interpreting the literature on vision and driving. Surv Ophthalmol 2015;60:250-62

22. Anstey KJ, Eramudugolla R, Ross LA, et al. Road safety in an aging population: risk factors, assessment, interventions, and future directions. Int Psychogeriatr 2016;28:349-56.

23. Owsley C, McGwin G. Vision and driving. Vision Res 2010;50:2348-61.

24. Keeffe JE, Jin CF, Weih LM, et al. Vision impairment and older drivers: who's driving? Br J Ophthalmol 2002;86:1118-21.

25. Cross JM, McGwin G, Rubin GS, et al. Visual and medical risk factors for motor vehicle collision involvement among older drivers. Br J Ophthalmol 2009;93:400-4.

26. O'Byrne C, Naughton A, O'Neill D. Is driver licensing restriction for age-related medical conditions an effective mechanism to improve driver safety without unduly impairing mobility? Eur Geriatr Med 2015;6:541-4.

27. Molina-Torres MJ, Crespo MS, Francés AT, et al. Diagnosis accuracy of two vision screeners for visual health surveillance of workers who use video display terminals. J Occup Health 2016;58:444-51.

28. Dougherty BE, Flom RE, Bullimore MA. An evaluation of the mars letter contrast sensitivity test. Optom Vis Sci 2005;82:970-5.

29. Haymes SA, Roberts KF, Cruess AF, et al. The letter contrast sensitivity test: clinical evaluation of a new design. Invest Ophthalmol Vis Sci 2006;47:2739-45.
30. Khambhiphant B, Tulvatana W, Busayarat M. The new numbers contrast sensitivity chart for contrast sensitivity measurement. $J$ Optom 2011;4:128-33.

31. Green KA, McGwin G, Owsley C. Associations between visual, hearing, and dual sensory impairments and history of motor vehicle collision involvement of older drivers. J Am Geriatr Soc 2013;61:252-7.

32. Owsley C, Ball K, McGwin G, et al. Visual processing impairment and risk of motor vehicle crash among older adults. JAMA 1998;279:1083-8.

33. Edwards JD, Ross LA, Wadley VG, et al. The useful field of view test: normative data for older adults. Arch Clin Neuropsychol 2006;21:275-86.

34. Bernstein IH, Lacritz L, Barlow CE, et al. Psychometric evaluation of the Montreal Cognitive Assessment (MoCA) in three diverse samples. Clin Neuropsychol 2011;25:119-26.

35. Vaucher P, Herzig D, Cardoso I, et al. The trail making test as a screening instrument for driving performance in older drivers; a translational research. BMC Geriatr 2014;14:123.

36. Hofheinz M, Mibs M. The prognostic validity of the timed up and go test with a dual task for predicting the risk of falls in the elderly. Gerontol Geriatr Med 2016;2:233372141663779.

37. Vaucher P, Cardoso I, Veldstra JL, et al. A neuropsychological instrument measuring age-related cerebral decline in older drivers: development, reliability, and validity of MedDrive. Front Hum Neurosci 2014:8:772.

38. McGwin G, Chapman V, Owsley C. Visual risk factors for driving difficulty among older drivers. Accid Anal Prev 2000;32:735-44.

39. Lyman JM, McGwin G, Sims RV. Factors related to driving difficulty and habits in older drivers. Accid Anal Prev 2001;33:413-21.

40. Sandlin D, McGwin G, Owsley C. Association between vision impairment and driving exposure in older adults aged 70 years and over: a population-based examination. Acta Ophthalmol 2014:92:e207-e212.

41. West CG, Gildengorin G, Haegerstrom-Portnoy G, et al. Vision and driving self-restriction in older adults. J Am Geriatr Soc 2003:51:1348-55.

42. Man-Son-Hing M, Marshall SC, Molnar FJ, et al. Systematic review of driving risk and the efficacy of compensatory strategies in persons with dementia. J Am Geriatr Soc 2007;55:878-84.

43. Deutsche Ophtalmologische Gesellschaft. DOG-Kongress 2008 Rückblick. 2008 http://www.dog.org/?cat=115 (accessed 16 Jan 2017).

44. Bach M. The Freiburg visual acuity test--automatic measurement of visual acuity. Optom Vis Sci 1996;73:49-53.

45. Kimlin JA, Black AA, Djaja N, et al. Development and validation of a vision and night driving questionnaire. Ophthalmic Physiol Opt 2016:36:465-76.

46. Kimlin JA. Night driving and assessment of mesopic vision for older adults: Queensland University of Technology, 2016. Brisbane.

47. Owsley C, Stalvey B, Wells J, et al. Older drivers and cataract: driving habits and crash risk. J Gerontol A Biol Sci Med Sci 1999;54:M203-11. 